\title{
Calcitonin gene-related peptide stimulates BMP-2 expression and the differentiation of human osteoblast-like cells in vitro
}

\author{
Gang TIAN, Gang ZHANG, Ying-hui TAN* \\ Department of Stomatology, Xinqiao Hospital Affiliated to the Third Military Medicine College, Chongqing 400037, China
}

\begin{abstract}
Aim: To investigate whether bone morphogenic protein-2 (BMP-2) expression was involved in calcitonin gene-related peptide (CGRP)induced osteogenesis in human osteoblast-like cells in vitro.

Methods: MG-63 osteogenic human osteosarcoma cells were treated with CGRP $\left(10^{-8} \mathrm{~mol} / \mathrm{L}\right)$ for $48 \mathrm{~h}$. Cell cycle phases were determined using flow cytometry assay. The protein levels of BMP-2, ALP, Osteocalcin, Colla1, CREB, and pCREB were measured with Western blotting, while the mRNA level of BMP-2 was measured with qR-T PCR. The expression of ALP in MG-63 cells was also studied using immunofluorescence staining. The level of cAMP was measured with ELISA assay.

Results: CGRP treatment significantly stimulated proliferation of MG-63 cells, and increased the expression of BMP-2 and the osteogenic proteins ALP, Osteocalcin and Colla1. Pretreatment with the BMP signaling inhibitor Noggin (100 ng/mL) did not affect CGRPstimulated proliferation and BMP-2 expression, but abolished the CGRP-induced increases of the osteogenic proteins ALP, Osteocalcin and Colla1. Furthermore, CGRP treatment markedly increased cAMP level in MG-63 cells, whereas pretreatment with the cAMP pathway inhibitor $\mathrm{H} 89$ ( $5 \mu \mathrm{mol} / \mathrm{L}$ ) abolished the CGRP-induced increases of cAMP level and BMP-2 expression.

Conclusion: In MG-63 cells, the BMP pathway is involved in CGRP-induced osteogenic differentiation but not in proliferation, whereas the $\mathrm{CAMP} / \mathrm{pCREB}$ pathway is involved in the expression of BMP-2.
\end{abstract}

Keywords: c calcitonin gene-related peptide; Noggin; H89; MG-63 human osteosarcoma cell; osteogenesis; bone morphogenic protein; CAMP/pCREB pathway

Acta Pharmacologica Sinica (2013) 34: 1467-1474; doi: 10.1038/aps.2013.41; published online 27 May 2013

\section{Introduction}

Sensory nerve activation has a centrally mediated but poorly understood action on bone. The relative importance and interactions between autonomic, sensory, and peripheral nervous system actions on bone mass are not clear in healthy individuals and even less so in pathologic states. Understanding how the central nervous system integrates homeostatic signals with the regulation of bone homeostasis is an exciting research area.

Experimental evidence suggests that the nervous system is involved in bone remodeling. In response to fracture or other trauma, peripheral peptidergic neurons can influence osteoclast formation through the production of several neuropeptides. Calcitonin gene-related peptide (CGRP), a 37-residue peptide generated in specific neurons by alternative splicing of the calcitonin gene, is an important neuropeptide expressed

\footnotetext{
* To whom correspondence should be addressed.

E-mail tanyhoms@yahoo.cn

Received 2012-10-30 Accepted 2013-03-25
}

in nerve fibers during bone development and repair ${ }^{[1,2]}$.

Numerous in vivo studies have suggested that CGRP is associated with bone development, metabolism and repair. In vitro studies have demonstrated that CGRP stimulates osteoblast proliferation, differentiation and maturation in both osteoblast cell lines and bone marrow mesenchyme stromal cells. CGRP and its receptors have been identified in the $\left[\mathrm{Ca}^{2+}\right]_{\mathrm{i}}$ (intracellular $\left.\mathrm{Ca}^{+}\right)^{[3]}$, cAMP (cyclic adenosine monophosphate) ${ }^{[4]}$, PKC (protein kinase $C)^{[5]}$, MAPK (mitogen-activated protein kinase $)^{[2,6]}$, and ERK (extracellular signal-regulated protein kinase) signal transduction pathways ${ }^{[7]}$.

Although CGRP is a recognized neuromodulator of osteoblast cell signaling, its mechanism of action in osteogenesis remains elusive. In vivo studies have shown that CGRP regulates osteoblast differentiation by 1) CGRP receptors localized on the osteoblast surface and 2) immune responses via many other factors in callus, such as cytokines, growth factors and the bone matrix itself. CGRP influences bone remodeling through the release of diverse growth factors, such as IGF-1 ${ }^{[8,9]}$, TNF ${ }^{[10,11]}$, IL-6, and IL-1 ${ }^{[10,11]}$. However, the role of 
bone morphogenetic proteins (BMPs) in the regulatory mechanism of CGRP on osteoblasts has not been systematically studied.

BMPs are multi-functional growth factors that belong to the transforming growth factor beta (TGF- $\beta$ ) superfamily. The functions of BMPs in embryonic development and postnatal and adult animals have been extensively studied in recent years. Among the BMPs, BMP-2 has very strong osteoinductive activity. Both in vivo and in vitro studies have shown that BMP-2 is an essential regulator during the induction of osteogenic differentiation and bone formation ${ }^{[12-15]}$. Bone marrow mesenchyme stromal cells (BM-MSCs) effectively support bone formation via autocrine and paracrine functions when selectively facilitating the delivery and bioavailability of BMP$2^{[16]}$. BMP-2 promotes the proliferation of pre-osteoblast cells, induces the osteogenic or chondrogenic differentiation of mesenchymal cells ${ }^{[17,18]}$, and improves the osteogenic phenotype and capacity of stem cells through increased ALP activity and osteocalcin mRNA expression. Signal transduction studies have revealed that the Smad and P38MAPK pathways are immediately downstream of BMP receptors and that they play central roles in BMP signal transduction ${ }^{[4,19-21]}$.

To date, studies of the relationship between BMPs and CGRP are limited. Previous studies suggest that BMPs 2, 4, or 6 stimulate CGRP expression in $60 \%$ of DRG neurons ${ }^{[22]}$. While CGRP promotes the production of BMP-2 in pulp cells $^{[23,24]}$, BMP-2 is also associated with the spatial and temporal regeneration of CGRP-positive nerve fibers in ectopic bone formation $^{[25]}$. Neuropeptides and receptors such as CGRP play important roles in the regulation of bone remodeling ${ }^{[1]}$, and CGRP induces BMP-2 expression in bone tissues ${ }^{[23,26]}$. We hypothesized that BMP-2 expression is involved in CGRPinduced osteogenesis.

\section{Materials and methods Drugs}

Human CGRP, noggin (BMP signaling antagonist), and H89 were purchased from Sigma-Aldrich (St Louis, MO, USA). A cAMP ELISA kit was purchased from R\&D Systems. Polyclonal rabbit anti-pCREB and anti-CREB antibodies were purchased from New England Biolabs (Ipswich, MA, USA). CGRP was dissolved in distilled water to a stock concentration of $100 \mathrm{mmol} / \mathrm{L}$ and stored in $100-\mathrm{mL}$ aliquots at $-70^{\circ} \mathrm{C}$.

\section{MG-63 cell culture and CGRP treatment}

Low-passage MG-63 osteogenic human osteosarcoma cells were obtained from the Shanghai Institutes for Biological Sciences, Chinese Academy of Sciences (Shanghai, China) and maintained in Gibco RPMI-1640 medium with 10\% FBS (Life Tech, Foster City, CA, USA). Cells were normally plated at a density of $5 \times 10^{5}$ cells $/ \mathrm{cm}^{2}$ and cultivated in humidified $5 \%$ $\mathrm{CO}_{2}$ at $37^{\circ} \mathrm{C}$. Cultures were never allowed to become confluent. After $24 \mathrm{~h}$ in fresh RPMI-1640, cells were treated with RPMI-1640 with 10\% FBS and the CGRP mixture at a final concentration of $10^{-8} \mathrm{~mol} / \mathrm{L}$. CGRP treatment lasted for $48 \mathrm{~h}$, and RPMI-1640 with 10\% FBS was used as a control ${ }^{[27,28]}$. For the assays described below, cells were grown on sterile 1-mmthick, 23-mm-diameter circular coverslips. All assays were performed in PBS.

\section{Cell cycle flow cytometry assay}

After the 48-h CGRP treatment, cells were harvested with Gibco Trypsin-EDTA (Life Tech) and fixed with ice-cold 70\% ethanol at $4^{\circ} \mathrm{C}$ for $30 \mathrm{~min}$. After washing with PBS, cells were incubated with $1 \mathrm{mg} / \mathrm{mL}$ RNase A (Sigma-Aldrich) at $37^{\circ} \mathrm{C}$ for $30 \mathrm{~min}$. Cells were collected by centrifugation at 2000 rounds per minute for $5 \mathrm{~min}$ and then stained with a DNA staining solution $(250 \mu \mathrm{L})$ for $3 \mathrm{~min}$ in the dark at room temperature $\left(25^{\circ} \mathrm{C}\right)$. The nuclear DNA content of cells was measured at high speed with a FACSCalibur flow cytometer (BD Biosciences, San Jose, CA, USA). The distribution of cell cycle phases was determined by Modfit software (BD Biosciences).

\section{Western blotting}

Western blots were performed as described previously. Briefly, MG-63 cells were washed and lysed in cold solution of $50 \mathrm{mmol} / \mathrm{L}$ Tris-HCl (pH 7.4), $10 \mathrm{mmol} / \mathrm{L}$ EDTA, $4.3 \mathrm{~mol} / \mathrm{L}$ urea, and $1 \%$ Triton $\mathrm{X}-100$. Protein samples were subjected to SDS-polyacrylamide (10\%) gel electrophoresis and transferred onto a nitrocellulose membrane. The membrane was blocked with 5\% BSA in Tris-buffered saline with Tween 20 (TBS-T) for $2 \mathrm{~h}$ at room temperature $\left(25^{\circ} \mathrm{C}\right)$. The blots were incubated at $4^{\circ} \mathrm{C}$ overnight with primary antibodies against BMP-2, ALP, Osteocalcin, CREB, pCREB, $\beta$-actin (Epitomics, Burlingame, CA, USA), and Colla1 (Santa Cruz Biotechnology, Santa Cruz, CA, USA) diluted in TBS-T. After washing and incubation with the goat anti-rat HRP-conjugated secondary antibodies (Sigma), the blots were visualized with an ECL kit. $\beta$-Actin protein expression was used as an internal control.

\section{Quantitative real-time PCR (qRT-PCR)}

Total RNA was isolated and converted to cDNA. According to the manufacturer's protocols, the cDNA was PCR-amplified on a 7500/7500 Fast Real-Time PCR System (Life Tech, Foster, CA, USA) with $0.5 \mathrm{mmol} / \mathrm{L} \mathrm{BMP-2}$ primers (Forward: 5'-ACCCGCTGTCTTCTAGCGT-3'; Reverse: 5'-TTTCAGGCCGAACATGCTGAG-3'; 180-bp product). The RT reaction included $1 \mu \mathrm{g}$ of total RNA and was performed at $35^{\circ} \mathrm{C}$ for 15 min followed by $85^{\circ} \mathrm{C}$ for $5 \mathrm{~s}$; the cDNA was then stored at $4{ }^{\circ} \mathrm{C}$ temporarily. The PCR reactions were performed in a GeneAmp PCR System 9600 thermal cycler (Life Tech) in triplicate with the following conditions: $95^{\circ} \mathrm{C}$ for $30 \mathrm{~s}$ followed by 40 cycles of denaturation at $95^{\circ} \mathrm{C}$ for $6 \mathrm{~s}$, extension at $60^{\circ} \mathrm{C}$ for $20 \mathrm{~s}$, and single signal acquisition for $10 \mathrm{~s}$. GAPDH was used as an internal control.

\section{Immunofluorescence staining}

MG-63 cells were fixed with 4\% paraformaldehyde in PBS for $15 \mathrm{~min}$ and permeabilized with $0.1 \%$ Triton X-100 for $15 \mathrm{~min}$ at room temperature. After washing in PBS, specific binding sites were blocked with $5 \%$ BSA in PBS for $1 \mathrm{~h}$ at $4^{\circ} \mathrm{C}$. The cells were incubated with primary (human ALP; eBioscience, 
San Diego, CA, USA) and secondary (FITC-conjugated goat anti-rat antibody; Santa Cruz Biotechnology) antibodies for $1 \mathrm{~h}$ at room temperature and stained with DAPI (Santa Cruz Biotechnology). The cells were visualized with a TCS SP2 confocal microscope (Leica, Tokyo, Japan).

\section{cAMP assay}

ELISAs were performed for quantification of cAMP. After CGRP treatment for $48 \mathrm{~h}$, cells were harvested, and cAMP was quantified with a cAMP ELISA kit (R\&D Systems) following the manufacturer's protocol.

\section{Statistical analysis}

Data were expressed as mean $\pm S D$. Statistical comparisons of the results were performed using analysis of variance. Significant differences $(P<0.05)$ between the mean values of control and test groups were analyzed by Dunnett's test.

\section{Results}

CGRP induces the proliferation and differentiation of MG-63 cells CGRP promotes MG- 63 cell proliferation

As shown in Figure 1A and 1B, flow cytometry-based DNA content analysis indicated that the percentage of cells at $S / G_{2}$ phase was significantly higher in CGRP-treated cells than in the control group. These data suggested that CGRP promoted MG-63 cell proliferation.

\section{CGRP enhances the osteoblast differentiation of MG-63 cells}

After $48 \mathrm{~h}$ of CGRP treatment, we assessed the protein expression levels of ALP, Colla1 and Osteocalcin (OCN) by Western blotting, and ALP expression was also measured by immunofluorescent staining of MG-63 cells. CGRP significantly induced ALP (Figure 2A and 2B), Osteocalcin (Figure 2D), and Colla1 (Figure $2 \mathrm{C}$ ) expression $(P<0.05)$, suggesting that CGRP induced osteogenesis in MG-63 cells.

CGRP induces MG-63 cell differentiation but not proliferation through a BMP-2 dependent pathway

BMP pathway is not involved in the CGRP-induced proliferation of MG-63 cells

BMP-2 expression in osteoblasts enhances osteogenic differentiation in vitro and bone formation ${ }^{[29]}$. To determine the role of the BMP pathway in CGRP-induced MG-63 cell proliferation, cells were pretreated with $100 \mathrm{ng} / \mathrm{mL}$ Noggin, a soluble

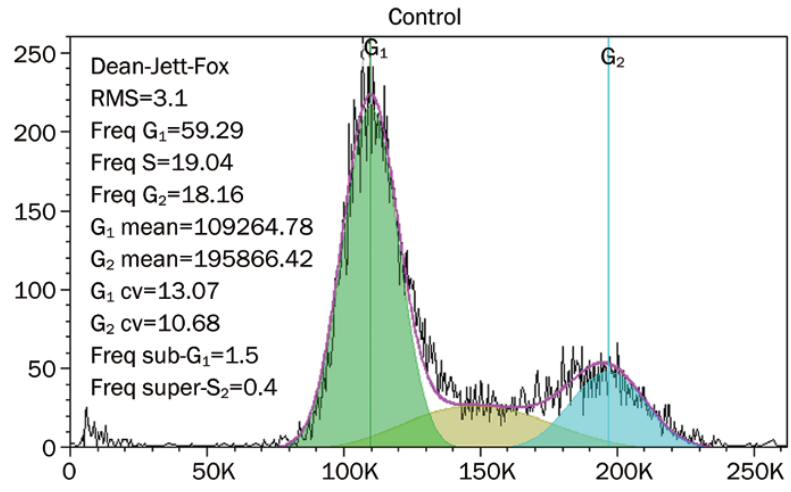

B

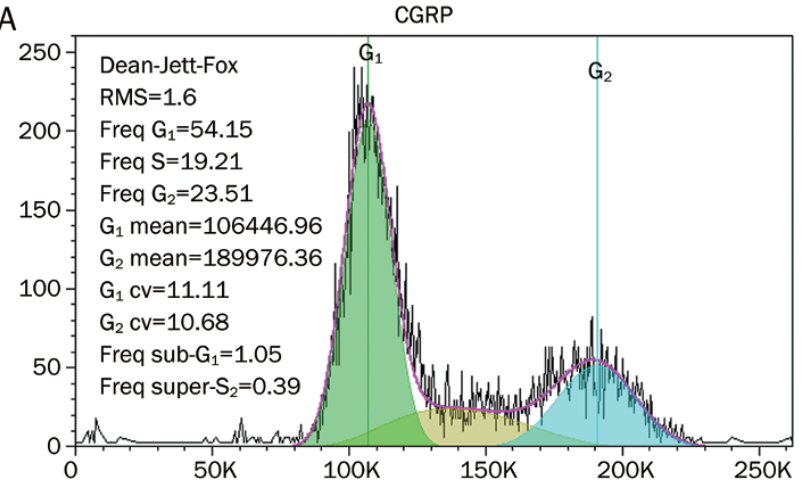

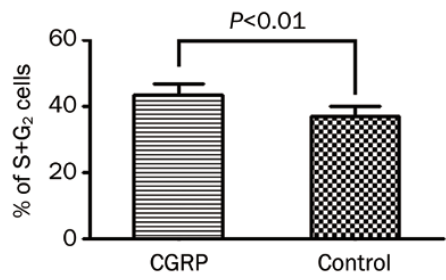

Figure 1. Effect of CGRP on the proliferation of MG-63 cells. (A) Flow cytometry of MG-63 cells treated with CGRP (left) and with control medium (right). (B) The percentages of cells at the $S / G_{2}$ phase in CGRPtreated MG-63 cells and the control group are shown as the mean \pm SD of 4 independent samples $(P<0.01)$.
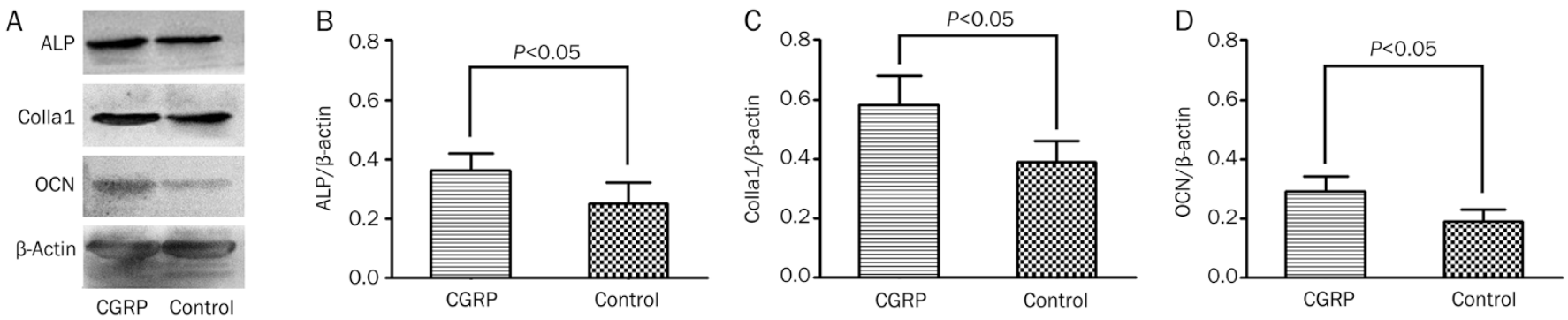

Figure 2. Western blot analysis for the expression of several osteogenic proteins including ALP, Colla1, and OCN in the CGRP-treated MG-63 cells. $\beta$-Actin was used as an internal control. (B-D) Western blots were quantified via densitometry scanning using NIH Image software and plotted in histograms representing mean \pm SD. Data were obtained from 4 independent experiments. 
inhibitor of BMP signaling, for $30 \mathrm{~min}$ and then incubated with $10^{-8} \mathrm{~mol} / \mathrm{L}$ CGRP for $48 \mathrm{~h}$. The proportion of cells in various stages of the cell cycle was examined by flow cytometry. Figure $3 \mathrm{~A}$ and $3 \mathrm{~B}$ shows that Noggin pretreatment did not significantly alter the percentage of cells at the $S / G_{2}$ phase in the CGRP-treated group. However, qRT-PCR (Figure 4A) showed that BMP-2 mRNA increased after stimulation with CGRP, regardless of Noggin pretreatment. Thus, CGRP increased BMP-2 expression, but the CGRP-induced proliferation of MG-63 cells was not mediated by the BMP-2 pathway.

\section{BMP pathway is involved in the CGRP-induced osteogenic} differentiation of MG-63 cells

To determine whether the BMP pathway was involved in CGRP-induced osteogenic differentiation of MG-63 cells, the cells were pretreated with Noggin and incubated with $10^{-8}$ $\mathrm{mol} / \mathrm{L}$ CGRP for $48 \mathrm{~h}$. Cells were examined for ALP expression by anti-ALP (green) immunofluorescence staining (Figure 5), and the induced BMP-2 and osteogenic proteins were quantified by Western blot (Figure 4B, 4C, and Figure 6). As shown in Figure 4C, BMP-2 expression was not significantly different between control and Noggin-treated groups or between CGRP- and CGRP/Noggin-treated groups, indicating that inactivation of the BMP-2 pathway did not alter the expression of BMP-2. This result also suggests that the expression of CGRP-induced BMP-2 protein does not require activation of the BMP pathway.

In contrast, Noggin significantly decreased the expression of osteogenic proteins (ALP, ColIa1, and OCN) in CGRP-treated MG-63 cells compared with the CGRP-treated group (Figure $6 \mathrm{~B}-6 \mathrm{D})$. Blocking the BMP-2 pathway decreased the expression of differentiation-related proteins, indicating that BMP pathway activation leads to CGRP mediated-osteogenic differentiation in MG-63 cells.

CGRP upregulates BMP-2 expression by cAMP/pCREB signaling in MG-63 cells

cAMP/PCREB activation induces CREB phosphorylation, leading to the initiation of protein transcription. To investigate whether the $\mathrm{CAMP} / \mathrm{PCREB}$ pathway was responsible
A

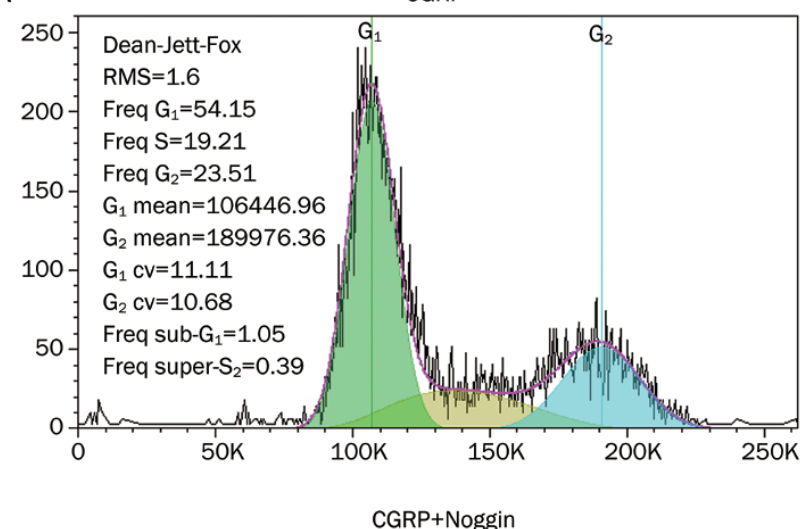

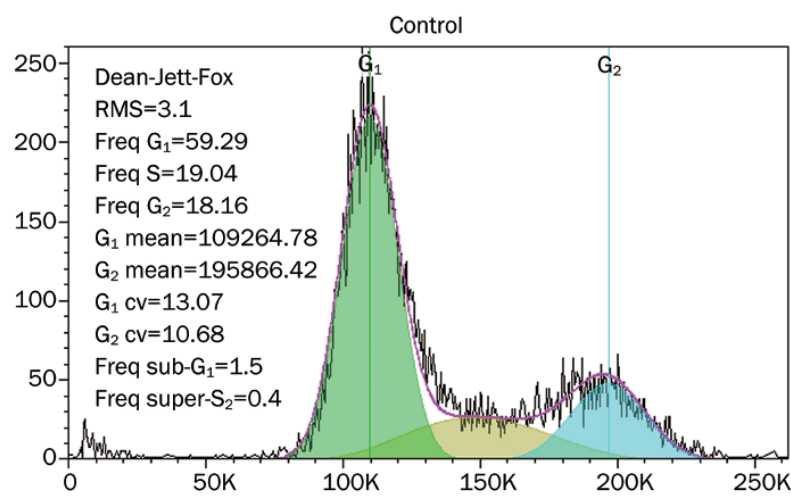

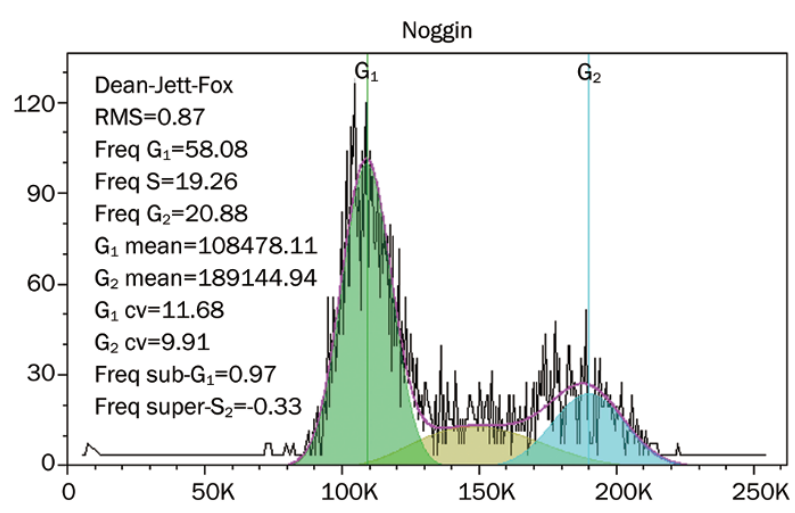

B

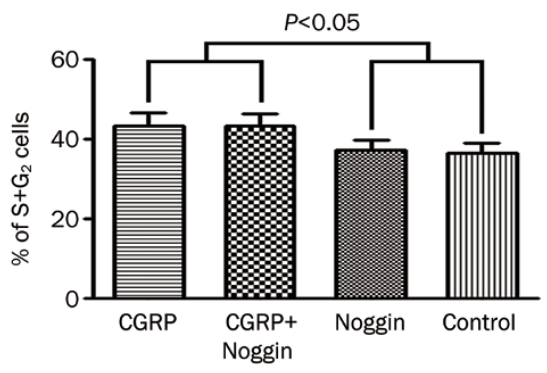

Figure 3. Effect of BMP pathway inhibition on CGRP-induced MG-63 cell proliferation and BMP-2 expression. MG-63 cells were pre-treated with BMP pathway inhibitors (100 ng/mL Noggin) before treatment with $10^{-8}$ $\mathrm{mol} / \mathrm{L}$ CGRP. (A) Flow cytometry analysis of the cell cycle in four groups. (B) The percentages of Noggin pre-treated, CGRP-induced MG-63 cells at the $S / G_{2}$ phase are not significantly different from the CGRP group, but a significant difference between the Noggin pre-treated and non-induced control group $(P<0.05)$. Results are shown as mean \pm SD of 4 independent samples. 
A
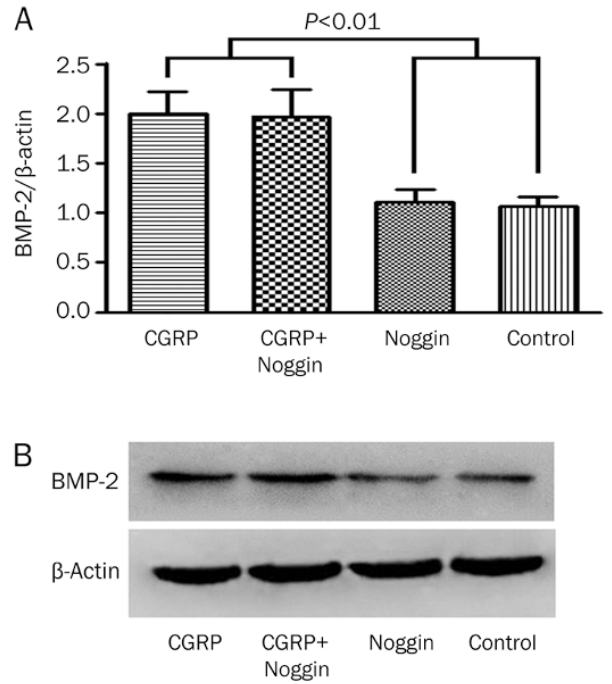

C

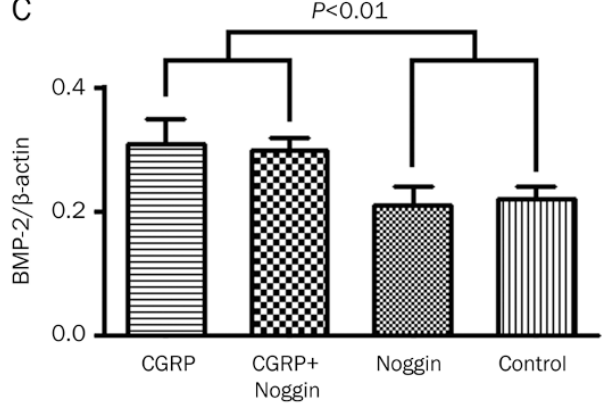

Figure 4. Expression of BMP-2 in 4 groups of MG-63 cells. (A) Densitometry of the RT-qPCR products normalized to GAPDH. BMP-2 expression was increased in both CGRP and CGRP+Noggin groups, with significant differences when compared with the Noggin and control groups $(P<0.01)$. (B) Western blot for BMP expression in the different treatment groups; $\beta$-actin was used as an internal control. (C) Western blots were quantified via densitometry scanning using NIH Image software and plotted in histograms representing 4 mean \pm SD. Data were obtained from 4 independent experiments.

for CGRP-induced BMP-2 expression, MG-63 cells were pretreated with $\mathrm{H}-89$, a selective inhibitor of cAMP-dependent protein kinase A, for $30 \mathrm{~min}$ and then exposed to CGRP for $48 \mathrm{~h}$. We examined the levels of cAMP by ELISA, phosphorylated-CREB ( $p$-CREB) and total CREB by Western blot, and BMP-2 by qRT-PCR and Western blot. As shown in Figure 7A, cAMP levels in CGRP-treated MG-63 cells were significantly higher than that in the control cells. Pretreatment with $\mathrm{H}-89$ did not significantly influence the cAMP level in CGRPtreated cells, suggesting that CGRP stimulated the expression of cAMP.

In addition, CGRP significantly upregulated the expression of BMP-2 mRNA and protein (Figure 7B, 7C, and 7D). H-89 inhibited the CGRP-induced upregulation of BMP-2 mRNA and protein (Figure 7B and 7D), indicating that CAMPdependent phosphorylation might be involved in CGRPinduced BMP-2 expression. Furthermore, pCREB but not
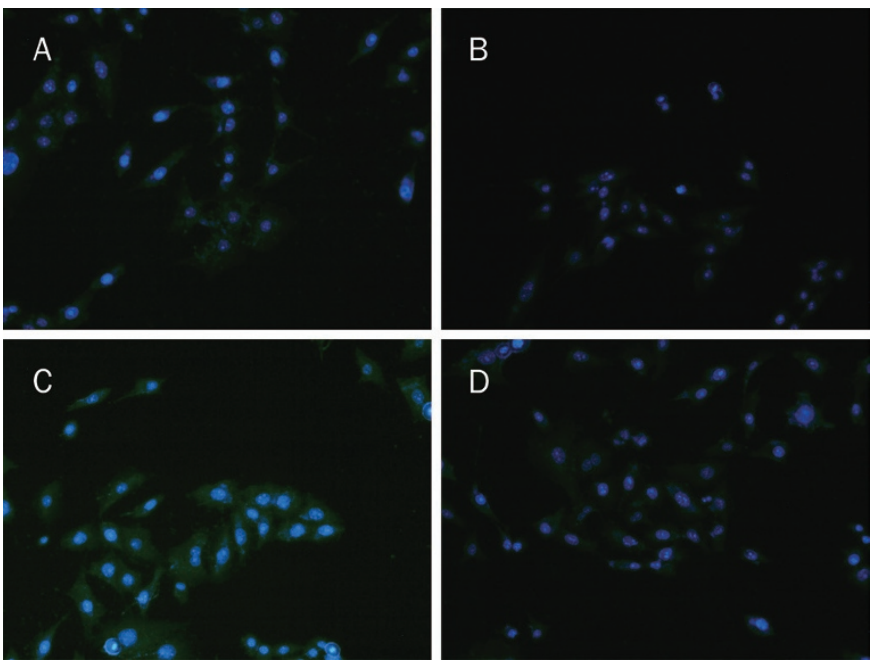

Figure 5. Immunofluorescence staining of ALP (green) in control (A), Noggin- (B), CGRP- (C), and CGRP+Noggin- (D) treated MG-63 cells (DAPI nuclear staining, blue). Magnification, 100×.

CREB was increased by CGRP and decreased by H-89 (Figure 7E, 7F, and 7G). Altogether, these results suggested that CGRP upregulated BMP-2 expression through cAMP/PCREB signaling in MG-63 cells.

\section{Discussion}

CGRP, a member of the calcitonin peptide family, has been recognized in both in vitro and in vivo studies as a neurotransmitter involved in the osteoblast proliferation and bone remodeling ${ }^{[30]}$. However, the potential mechanisms of CGRP during osteoblast proliferation and differentiation have not been widely investigated. In this study, we determined how CGRP influences MG-63 cell proliferation and differentiation. We found that the CGRP-induced osteoblast cell proliferation was not BMP pathway-dependent. However, CGRPinduced differentiation-specific markers (ALP, collagen I and $O C N$ ) required activation of the BMP pathway. We also found that CGRP increased the mRNA and protein levels of BMP-2 in MG-63 cells. Furthermore, we demonstrated that the cAMP/pCREB pathway was involved in CGRP-induced BMP-2 expression. As expected, CGRP-induced cAMP synthesis enhanced CREB phosphorylation, resulting in increased expression of BMP-2.

The regulation of metabolism and fracture healing of bone tissue by the nervous system is closely related to the regulation of CGRP in osteoblasts. CGPR stimulates osteoblast proliferation and differentiation both in vivo and in vitro. However, these data are inconsistent in different cell lines. In the study of neural bone physiology, the human osteosarcoma cell line MG-63 is often used as an osteoblast-like cell model due to its relatively low degree of differentiation ${ }^{[31]}$. Additionally, the CGRP receptor can be detected on the MG-63 cell surface, and the downstream signal pathway is relatively well known ${ }^{[3,32]}$. Our previous study demonstrated that the osteoblast-specific expression of ALP, Colla1, and OCN in MG-63 cells increased 

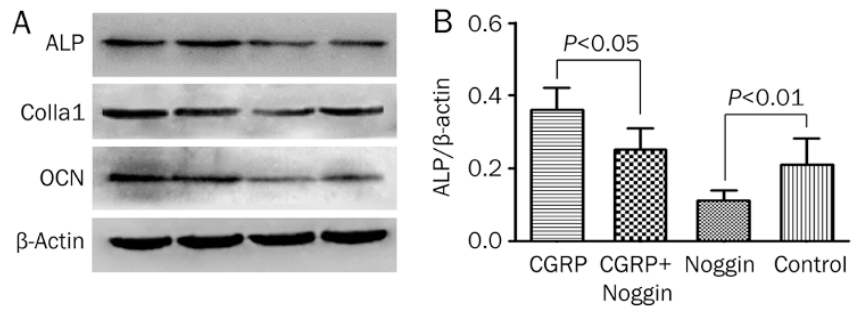
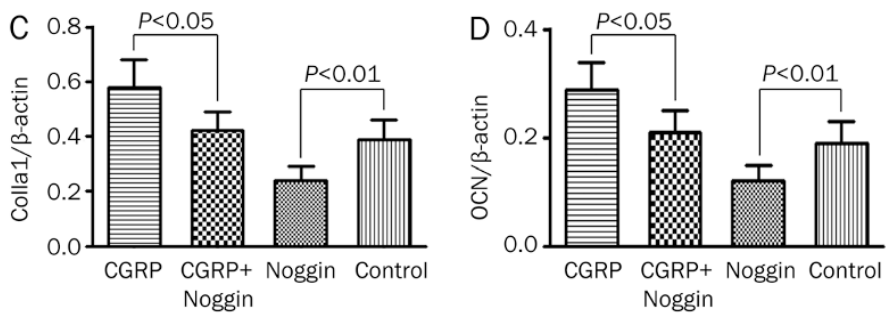

Figure 6. The effect of the BMP pathway on CGRP-induced MG-63 cell differentiation. MG-63 cells were pre-treated with the BMP pathway inhibitor Noggin $\left(100 \mathrm{ng} / \mathrm{mL}\right.$ ) before treatment with $10^{-8} \mathrm{~mol} / \mathrm{L}$ CGRP. (A) Western blot for BMP-2 and osteogenic proteins ALP, Colla1, and OCN in the different treatment groups. $\beta$-Actin was used as an internal control. (B-D) Western blots were quantified via densitometry scanning using NIH Image software, and the data were plotted in histograms showing mean \pm SD. Data were obtained from 4 independent experiments. The expression of osteogenic proteins including ALP, Colla1, and OCN decreased in both CGRP+Noggin and Noggin groups, with significant differences when CGRP vs CGRP+Noggin and Noggin vs control were compared $(P<0.05)$.

A
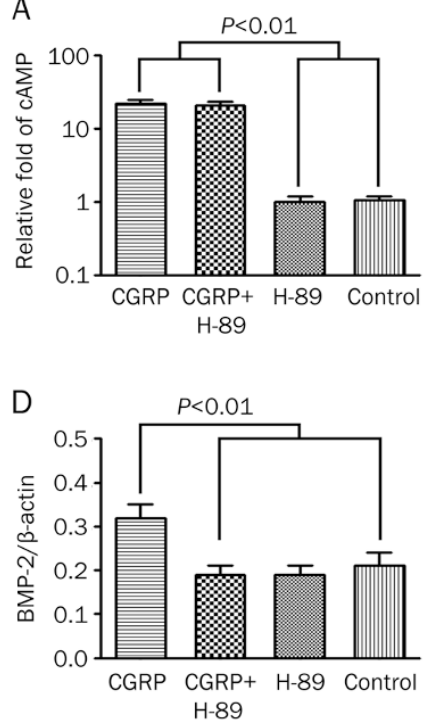

B

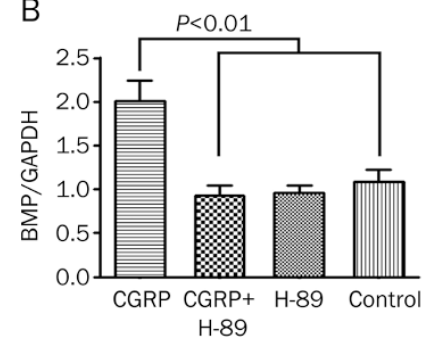

E

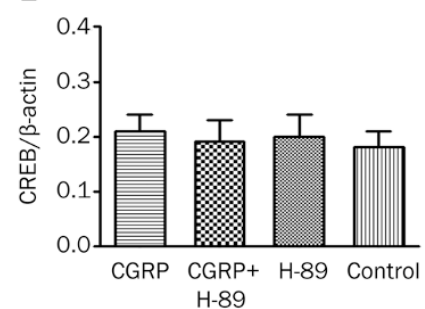

C

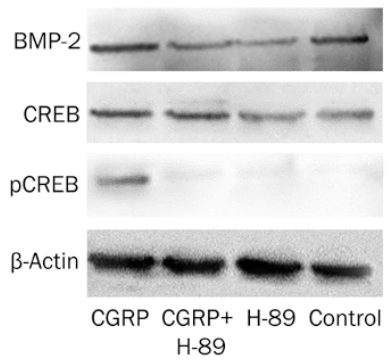

$\mathrm{F}$

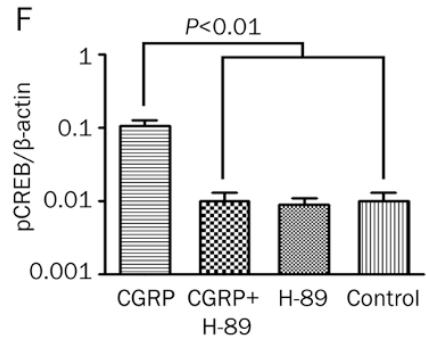

G

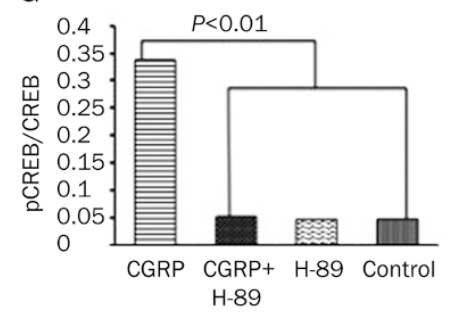

Figure 7. CAMP/CREB pathway involvement in CGRP-induced BMP-2 expression. MG- 63 cells were divided into the following four treatment groups: $10^{-8}$ $\mathrm{mol} / \mathrm{L} \mathrm{CGRP,} 10^{-8} \mathrm{~mol} / \mathrm{L} \mathrm{CGRP}+5 \mu \mathrm{mol} / \mathrm{L} \mathrm{H}-89,5 \mu \mathrm{mol} / \mathrm{L} \mathrm{H}-89$ and control. (A) ELISA of CAMP concentrations. (B) qRT-PCR analysis of BMP-2 mRNA in the total RNA isolated from MG-63 cells. GAPDH was used as an internal control. (C) Western blot for BMP-2, CREB, and p-CREB in MG-63 cells. $\beta$-Actin was the internal control. The Western blot results were quantified and plotted in histograms representing mean $\pm S D$. Data were obtained from 4 independent experiments. (D) The expression of BMP-2 was significantly increased in the CGRP-treated group compared with the other groups $(P<0.01)$. (E) The expression of CREB did not differ in 4 groups. (F) The expression of phosphorylated CREB (pCREB) was significantly increased in the CGRP treated group and was inhibited in $\mathrm{H}-89$ pretreated group $(P<0.01)$. (G) The ratio of pCREB/CREB in CGRP treated group was significantly increased.

with the concentration of CGRP. Thus, we selected MG-63 instead of other osteoblast cell lines as our model in this study.

In our previous studies, we found a time- and dose-dependence during the CGRP-stimulated differentiation and proliferation of MG-63 $3^{[27,28]}$. Of various CGRP concentrations $\left(10^{-7}\right.$ $10^{-9}$, and $10^{-10} \mathrm{~mol} / \mathrm{L}$ ) and exposure times tested, CGRP treatment at $10^{-8} \mathrm{~mol} / \mathrm{L}$ for $24-48 \mathrm{~h}$ was most effective in stimulating proliferation and differentiation of MG-63. We used these conditions in the current study to guarantee the positive effect of CGRP.

Our previous MTT assay also indicated that after 24-72 h the proliferation capacity was significantly higher in the CGRP-treated group than that in controls. However, prop- idium iodide staining indicated that more cells died after 48 $\mathrm{h}$ of CGRP incubation. Previous inconsistent results without time points were not reliable ${ }^{[2]}$. Thus, a delayed detection time point might erroneously suggest that CGRP does not affect osteoblast proliferation.

BMP signaling is involved in the maturation of stem cells into chondrocytes, osteoblasts, and osteocytes ${ }^{[33]}$ and plays essential roles in early vertebrate embryogenesis events including limb development ${ }^{[34]}$, stimulation of collagen synthesis $^{[35]}$, alkaline phosphatase activity ${ }^{[36]}$, osteocalcin expression in chondroblasts/osteoblasts and other unrelated bone formation processes. A number of studies have confirmed that activation of osteoblastic CGRP receptors results in enhanced 
osteoblast proliferation $^{[8]}$, and CGRP also increases the synthesis of growth factors and cytokines [including IGF-1 (insulinlike growth factor)], collagen synthesis and bone formation in vivo ${ }^{[1]}$. However, the signaling pathways by which CGRP exerts its osteogenic effects in osteoblasts are unclear.

In this study, we employed MG-63, the human osteoblastlike cell line, to investigate the pathway activated in response to CGRP-induced cell proliferation and differentiation. We proved that CGRP promoted MG-63 cell entry to the $S / G_{2}$ cell cycle phase and stimulated the synthesis of osteogenic proteins and differentiation markers including ALP, Colla1 and OCN. Consistent with previous studies, our data suggested that CGRP promoted the proliferation and differentiation of osteoblasts. Furthermore, we demonstrated that the BMP pathway inhibitor Noggin significantly influenced the expression of ALP, ColIa1 and OCN but had no effect on CGRPinduced cell proliferation. However, Noggin did not inhibit CGRP-induced BMP-2 expression in MG-63. This result indicated that the BMP signaling pathway was not activated during CGRP-dependent osteoblast proliferation but was activated during CGPR-dependent osteoblast differentiation. Based on these findings, we hypothesize that the CGRP-promoted synthesis of BMP-2 may be dependent on a non-BMP route.

BMP-2 is a critical autocrine and paracrine growth factor that directs osteoblast differentiation and bone formation ${ }^{[37-39]}$. BMP-2 expression in osteoblasts promotes cell maturation and differentiation ${ }^{[40]}$. As we and others have shown, CGRP increases BMP-2 expression in osteoblasts ${ }^{[41]}$.

Increasing intracellular cAMP and calcium leads to changes in cell morphology and function ${ }^{[42,43]}$, but the effect of cAMP signaling on CGRP-dependent BMP-2 expression remains unclear. To examine these events, we examined the synthesis of BMP-2 mRNA and protein after pretreatment with the cAMP pathway inhibitor H-89. CGRP increased BMP-2 mRNA and protein expression in MG-63 cells, but these effects were significantly inhibited by $\mathrm{H}-89$, suggesting that activation of the CAMP pathway was required for CGRP-induced BMP-2 synthesis. We further determined that phosphorylated CERB played an essential role in this effect. Our data showed that CGRP induced BMP-2 expression via phosphorylated CREB and increased cAMP synthesis.

In summary, our findings confirm that CGRP increases proliferation and osteogenic differentiation in osteoblasts in vitro. Furthermore, CGRP-induced differentiation and proliferation of osteoblasts does not depend on the same BMP pathway. There may be another pathway besides the BMP pathway that contributes to CGRP-induced proliferation. We also provide compelling evidence for a mechanism by which CGRP promotes the BMP-2 expression in MG-63 cells through direct transactivation of $C A M P / P C R E B$ signaling. These data strongly support the hypothesis that CAMP pathwaydependent BMP-2 synthesis is important for osteogenesis.

\section{Acknowledgements}

This work is supported by the National Natural Science Foun- dation of China (Grant № 30973334 and 81271098).

\section{Author contribution}

Ying-hui TAN designed the study; Gang TIAN and Gang ZHANG performed the experiments; and Gang TIAN analyzed the data and prepared the manuscript.

\section{References}

1 Irie K, Hara-Irie F, Ozawa H, Yajima T. Calcitonin gene-related peptide (CGRP)-containing nerve fibers in bone tissue and their involvement in bone remodeling. Microsc Res Tech 2002; 58: 85-90.

2 Kawase T, Okuda K, Burns DM. Immature osteoblastic MG63 cells possess two calcitonin gene-related peptide receptor subtypes that respond differently to [Cys $(\operatorname{Acm})(2,7)]$ calcitonin gene-related peptide and CGRP(8-37). Am J Physiol Cell Physiol 2005; 289: C811-8.

3 Burns DM, Stehno-Bittel L, Kawase T. Calcitonin gene-related peptide elevates calcium and polarizes membrane potential in MG-63 cells by both cAMP-independent and -dependent mechanisms. Am J Physiol Cell Physiol 2004; 287: C457-67.

4 Villa I, Mrak E, Rubinacci A, Ravasi F, Guidobono F. CGRP inhibits osteoprotegerin production in human osteoblast-like cells via cAMP/ PKA-dependent pathway. Am J Physiol Cell Physiol 2006; 291: C52937.

5 Park KA, Fehrenbacher JC, Thompson EL, Duarte DB, Hingtgen CM, Vasko MR. Signaling pathways that mediate nerve growth factorinduced increase in expression and release of calcitonin gene-related peptide from sensory neurons. Neuroscience 2010; 171: 910-23.

6 Kawase T, Okuda K, Burns DM. Immature human osteoblastic MG63 cells predominantly express a subtype 1-like CGRP receptor that inactivates extracellular signal response kinase by a cAMP-dependent mechanism. Eur J Pharmacol 2003; 470: 125-37.

7 Yu SJ, Xia CM, Kay JC, Qiao LY. Activation of extracellular signalregulated protein kinase 5 is essential for cystitis- and nerve growth factor-induced calcitonin gene-related peptide expression in sensory neurons. Mol Pain 2012; 8: 48.

8 Ballica R, Valentijn K, Khachatryan A, Guerder S, Kapadia S, Gundberg $\mathrm{C}$, et al. Targeted expression of calcitonin gene-related peptide to osteoblasts increases bone density in mice. J Bone Miner Res 1999; 14: 1067-74.

9 Okajima K, Harada N. Promotion of insulin-like growth factor-I production by sensory neuron stimulation; molecular mechanism(s) and therapeutic implications. Curr Med Chem 2008; 15: 3095-112.

10 Millet I, Vignery A. The neuropeptide calcitonin gene-related peptide inhibits TNF-alpha but poorly induces IL-6 production by fetal rat osteoblasts. Cytokine 1997; 9: 999-1007.

11 Malemud CJ. Anticytokine therapy for osteoarthritis: evidence to date. Drugs Aging 2010; 27: 95-115.

12 Wang EA, Rosen V, D’Alessandro JS, Bauduy M, Cordes P, Harada T, et al. Recombinant human bone morphogenetic protein induces bone formation. Proc Natl Acad Sci U S A 1990; 87: 2220-4.

13 Cook SD, Wolfe MW, Salkeld SL, Rueger DC. Effect of recombinant human osteogenic protein-1 on healing of segmental defects in nonhuman primates. J Bone Joint Surg Am 1995; 77: 734-50.

14 Kim SE, Jeon O, Lee JB, Bae MS, Chun HJ, Moon SH, et al. Enhancement of ectopic bone formation by bone morphogenetic protein-2 delivery using heparin-conjugated PLGA nanoparticles with transplantation of bone marrow-derived mesenchymal stem cells. J Biomed Sci 2008; 15: 771-7.

15 Govender S, Csimma C, Genant HK, Valentin-Opran A, Amit Y, Arbel R, et al. Recombinant human bone morphogenetic protein-2 
for treatment of open tibial fractures: a prospective, controlled, randomized study of four hundred and fifty patients. J Bone Joint Surg Am 2002; 84-A: 2123-34.

16 Zhang Z, Li H, Ma Z, Feng J, Gao P, Dong H, et al. Efficient cardiomyogenic differentiation of bone marrow mesenchymal stromal cells by combination of Wnt11 and bone morphogenetic protein 2. Exp Biol Med (Maywood) 2012; 237: 768-76.

17 Guzzo RM, Gibson J, Xu RH, Lee FY, Drissi H. Efficient differentiation of human iPSC-derived mesenchymal stem cells to chondroprogenitor cells. J Cell Biochem 2013; 114: 480-90.

18 Karner E, Backesjo CM, Cedervall J, Sugars RV, Ahrlund-Richter L, Wendel M. Dynamics of gene expression during bone matrix formation in osteogenic cultures derived from human embryonic stem cells in vitro. Biochim Biophys Acta 2009; 1790: 110-8.

19 Villa I, Melzi R, Pagani F, Ravasi F, Rubinacci A, Guidobono F. Effects of calcitonin gene-related peptide and amylin on human osteoblastlike cells proliferation. Eur J Pharmacol 2000; 409: 273-8.

20 Handschel J, Berr K, Depprich RA, Kubler NR, Naujoks C, Wiesmann $\mathrm{HP}$, et al. Induction of osteogenic markers in differentially treated cultures of embryonic stem cells. Head Face Med 2008; 4: 10.

21 Villa I, Dal Fiume C, Maestroni A, Rubinacci A, Ravasi F, Guidobono F. Human osteoblast-like cell proliferation induced by calcitonin-related peptides involves PKC activity. Am J Physiol Endocrinol Metab 2003; 284: E627-33.

22 Wu Q, Sun CC, Lin HY, Babitt JL. Repulsive guidance molecule (RGM) family proteins exhibit differential binding kinetics for bone morphogenetic proteins (BMPs). PLoS One 2012; 7: e46307.

23 Calland JW, Harris SE, Carnes DL Jr. Human pulp cells respond to calcitonin gene-related peptide in vitro. J Endod 1997; 23: 485-9.

24 Park SH, Hsiao GY, Huang GT. Role of substance P and calcitonin gene-related peptide in the regulation of interleukin- 8 and monocyte chemotactic protein-1 expression in human dental pulp. Int Endod J 2004; 37: 185-92.

25 Wang XY, Guo X, Qu SX, Weng J, Cheng CY. Temporal and spatial CGRP innervation in recombinant human bone morphogenetic protein induced spinal fusion in rabbits. Spine 2009; 34: 2363-8.

26 Baldridge D, Shchelochkov O, Kelley B, Lee B. Signaling pathways in human skeletal dysplasias. Annu Rev Genomics Hum Genet 2010; 11: 189-217.

27 Li Y, Tan Y, Zhang G, Yang B, Zhang J. Effects of calcitonin generelated peptide on the expression and activity of nitric oxide synthase during mandibular bone healing in rabbits: an experimental study. J Oral Maxillofac Surg 2009; 67: 273-9.

28 Yan L, Yinghui T, Bo Y, Gang Z, Xian X, Lu Z. Effect of calcitonin generelated peptide on nitric oxide production in osteoblasts: an experimental study. Cell Biol Int 2011; 35: 757-65.
29 Huang W, Rudkin GH, Carlsen B, Ishida K, Ghasri P, Anvar B, et al. Overexpression of BMP-2 modulates morphology, growth, and gene expression in osteoblastic cells. Exp Cell Res 2002; 274: 226-34.

30 Naot D, Cornish J. The role of peptides and receptors of the calcitonin family in the regulation of bone metabolism. Bone 2008; 43: 813-8.

31 Ryu B, Li Y, Qian ZJ, Kim MM, Kim SK. Differentiation of human osteosarcoma cells by isolated phlorotannins is subtly linked to COX2, iNOS, MMPs, and MAPK signaling: implication for chronic articular disease. Chem Biol Interact 2009; 179: 192-201.

32 Morara S, Wang LP, Filippov V, Dickerson IM, Grohovaz F, Provini L, et al. Calcitonin gene-related peptide (CGRP) triggers $\mathrm{Ca}^{2+}$ responses in cultured astrocytes and in Bergmann glial cells from cerebellar slices. Eur J Neurosci 2008; 28: 2213-20.

$33 \mathrm{Li}$ Z, Chen YG. Functions of BMP signaling in embryonic stem cell fate determination. Exp Cell Res 2013; 319: 113-9.

34 Bobick BE, Cobb J. Shox2 regulates progression through chondrogenesis in the mouse proximal limb. J Cell Sci 2012; 125: 6071-83.

35 Araujo H, Fontenele MR, da Fonseca RN. Position matters: variability in the spatial pattern of BMP modulators generates functional diversity. Genesis 2011; 49: 698-718.

36 Sato C, Iwasaki T, Kitano S, Tsunemi S, Sano H. Sphingosine 1-phosphate receptor activation enhances BMP-2-induced osteoblast differentiation. Biochem Biophys Res Commun 2012; 423: 200-5.

37 Chen D, Zhao M, Mundy GR. Bone morphogenetic proteins. Growth Factors 2004; 22: 233-41.

38 Katagiri T, Yamaguchi A, Komaki M, Abe E, Takahashi N, Ikeda T, et al. Bone morphogenetic protein-2 converts the differentiation pathway of C2C12 myoblasts into the osteoblast lineage. J Cell Biol 1994; 127: 1755-66.

39 Wozney JM, Rosen V. Bone morphogenetic protein and bone morphogenetic protein gene family in bone formation and repair. Clin Orthop Relat Res 1998; 346: 26-37.

40 Kuo PL, Huang YT, Chang CH, Chang JK. Bone morphogenetic protein-2 and -4 (BMP-2 and -4 ) mediates fraxetin-induced maturation and differentiation in human osteoblast-like cell lines. Biol Pharm Bull 2006; 29: 119-24.

41 Zhang R, Oyajobi BO, Harris SE, Chen D, Tsao C, Deng HW, et al. Wnt/beta-catenin signaling activates bone morphogenetic protein 2 expression in osteoblasts. Bone 2013; 52: 145-56.

42 Schinke T, Liese S, Priemel M, Haberland M, Schilling AF, CatalaLehnen $\mathrm{P}$, et al. Decreased bone formation and osteopenia in mice lacking alpha-calcitonin gene-related peptide. J Bone Miner Res 2004; 19: 2049-56.

43 Zheng S, Li W, Xu M, Bai X, Zhou Z, Han J, et al. Calcitonin generelated peptide promotes angiogenesis via AMP-activated protein kinase. Am J Physiol Cell Physiol 2010; 299: C1485-92. 